\title{
Short-Term Forecasting of Electricity Consumption Revenue on Java-Bali Electricity System using Jordan Recurrent Neural Network
}

\author{
Tesa Eranti Putri ${ }^{1)^{*}}$, Aji Akbar Firdaus ${ }^{2)}$, Wilda Imama Sabilla ${ }^{3)}$ \\ ${ }^{1) 2) 3)}$ Department of Engineering, Faculty of Vocational Studies, Universitas Airlangga \\ Jl. Dharmawangsa Dalam No. 28-30, Surabaya, Indonesia \\ 1)tesaep@vokasi.unair.ac.id \\ 2)ajiakbarfirdaus11@gmail.com \\ ${ }^{3)}$ wildaimama@vokasi.unair.ac.id
}

Article history:
Received 19 July 2018
Revised 10 September 2018
Accepted 20 September 2018
Available online 28 October 2018

Keywords:

Electricity consumption Java-Bali Electricity System Jordan Recurrent Neural Network Revenue forecasting

\begin{abstract}
Depending on the day and time, electricity consumption tends to fluctuate and directly affects the amount of gained revenue for the company. To anticipate future economic change and to avoid losses in calculating the company's revenue, it is essential to forecast electricity consumption revenue as accurate as possible. In this paper, Jordan Recurrent Neural Network (JRNN) was used to do short term forecasting of the electricity consumption revenue from Java-Bali $500 \mathrm{kVA}$ electricity system. Seven JRNN models were trained using electricity consumption revenue between January-March 2012 to predict the revenue of the first week of April 2012. As performance comparators, seven traditional feed forward Artificial Neural Network (ANN) models were also constructed. The forecasting results were as expected for both models, where both producing steady repeating pattern for weekdays, but failed quite poorly to predict the weekends' revenue. This suggests that in Indonesia, weekends' electricity consumption revenue has different characteristics than weekdays. Evaluation of the prediction result was carried out using Sum of Square Error (SSE) and Mean Square Error (MSE). The evaluation showed that JRNN produced smaller SSE and MSE values than traditional feed forward ANN, thus JRNN could predict the electricity consumption revenue of Java-Bali electricity system more accurately.
\end{abstract}

\section{INTRODUCTION}

As one of the largest economy drivers in South East Asia, Indonesia has experienced steady raise in the sector of industry, economy, and development since the Asian financial crisis on the late 1990s. This growth is directly proportional to the electric power demands. In this modern era, electricity has become inseparable in our daily lives, powering from small portable gadgets to enormous machines in the factories. PT PLN (Persero), as the state company that handles all aspects of electricity in Indonesia, recorded a raise in electricity consumption every year, especially in the area of Java-Bali. It is no surprise, since more than a half of Indonesian reside in the area Java-Bali. Major economy activities also run in this area. Greater consumption equals greater load to generate and production cost, but on the other side it also improves the revenue of the company. An increase in revenue from this electricity consumption not only could cover the production cost, but also help funding future expansion and essential as one of the considerations in the company's decision-making.

It must be taken into account that electricity can't be stored for later use. Therefore, the electricity system must simultaneously generate active electric energy that is equal to the demand to maintain the balance [1]. Meanwhile, electricity consumption varies from time to time in a time span of an hour or a day, depending on several factors,

\footnotetext{
${ }^{*}$ Corresponding author
} 
such as the day of the week [2]. The revenue from electricity consumption is gained from multiplying the electricity rate or Tarif Dasar Listrik (TDL) with the amount of consumption. Hence, this electricity load fluctuation will affect the revenue directly. Accordingly, it is crucial to obtain the forecasting of total revenue from this electricity consumption load as accurate as possible to anticipate future economic change and avoid losses in calculating the company's revenue.

Since the electricity consumption revenue is closely related to the electricity load, some previous works regarding the subject of electricity load forecasting were inspected. Depending on the duration of observation, there are three types of forecasting: short-term (one day hourly forecast), medium-term (several days daily forecast), and long-term (one year or more forecast) [3]. Short-term forecasting is widely researched, since the result of this type of forecasting is necessary to discover fluctuate pattern and trends in electricity consumption for adequate scheduling and operation [2]. Meanwhile, several methods have been proposed to perform the task of short-term forecasting, which are divided into two major categories: (1) the statistical method and (2) the artificial intelligence machine learning method.

Recently, machine learning methods have gained more popularity and interest from the researchers. This is due to its flexibility to learn and adapt to any data [4]. A combination between Recurrent Support Vector Machines and Genetic Algorithm (RSVMG) were applied to modify learning function of a Recurrent Neural Network (RNN), which then used to forecast electricity load [5]. In [6], Interval type-2 Fuzzy Inference System was utilized to perform short-term load forecasting for Indonesian national holidays on Java-Bali electricity system. Here, it was also pointed that weekdays and weekends have notably different electricity load characteristic. Feature Selection which considered synergies between features to minimize error in prediction was proposed in [7] to forecast electricity load in US, Spain, and Europe. Fuzzy Logics combined with back propagation neural network and regression function was employed in [8]. The use of fuzzy in [8] enabled the model to produce a prediction of maximum and minimum value of the electricity load. Performance of 5 forecasting method from both the statistical and machine learning category were compared to find the best short-term load forecasting model in [9]. The 5 methods compared were Artificial Neural Network (ANN), Support Vector Regression, Random Forest Regression, eXtreme Gradient Boosting, and Flexible Neural Tree. All the models were tested on Spain's electricity load data and adjusted with same training metrics.

Amongst all the machine learning methods, ANN is frequently adopted to do short-term electricity load forecasting, since ANN is known to be capable to model non-linear problem for any kinds of data and to learn any complex function and approximate it with high precision [10], such as the electricity consumption load. Over the years, new types of ANN are developed and modified from traditional feed forward and back propagation ANN to increase the accuracy of its prediction result. Dynamic Neural Network and Advanced Wavelet Neural Network were employed in [11][12] to do the forecasting task. The recently popular kind of ANN, Deep Neural Network was modified and applied in [13] [14] [15] [16]. Deep Neural Network enables the model of multiple layers ANN to learn the representation of the data through pre-training the weights in each layer and applying the weight-tuning result to train the whole network again. Another kind of ANN which uses similar concept in training its model is the Recurrent Neural Network.

Recurrent Neural Network is a special kind of neural network that is developed on the concept that every unit is interconnected to form a cycle so that the output results are fed to the network again to tune the weight until the network is stable [17]. One interesting type of recurrent neural network is the Jordan Recurrent Neural Network (JRNN). JRNN utilizes an extra hidden layer, called context layer. Output results are copied to this context layer so that the weight of the unit in context layer stays in the value of 1 . The values from the context layer then are fed to the network again [18]. This kind of characteristic results in better model and thus a better and more accurate forecasting.

This research has two objectives. First is to perform short-term one day ahead electricity consumption revenue forecasting from Java-Bali electricity system. Indonesia's electricity consumption load pattern, particularly in JavaBali is distinct, as explained in [6]. Therefore, the JRNN model was borrowed to do the forecasting task. The second objective is to observe the performance of JRNN model on electricity consumption revenue data from Java-Bali electricity system, compared to traditional feed forward ANN. The forecasting model was trained using secondary data of electricity consumption from Java-Bali electricity system. The data was observed during January to March 2012. The model then tested to predict the data of electricity consumption for the first week of April 2012.

The rest of the paper is organized as follows. In section II, the methodology of the research is described. The testing of the forecasting model and the result are shown in section III. The test result is discussed in section IV and finally in section $\mathrm{V}$, the research is concluded. 


\section{METHODS}

The methodology of this research is presented in Fig. 1. There are 4 steps in the process: data preparation, model training, model testing, and evaluation of forecasted electricity consumption revenue. Each step will be explained in the following.

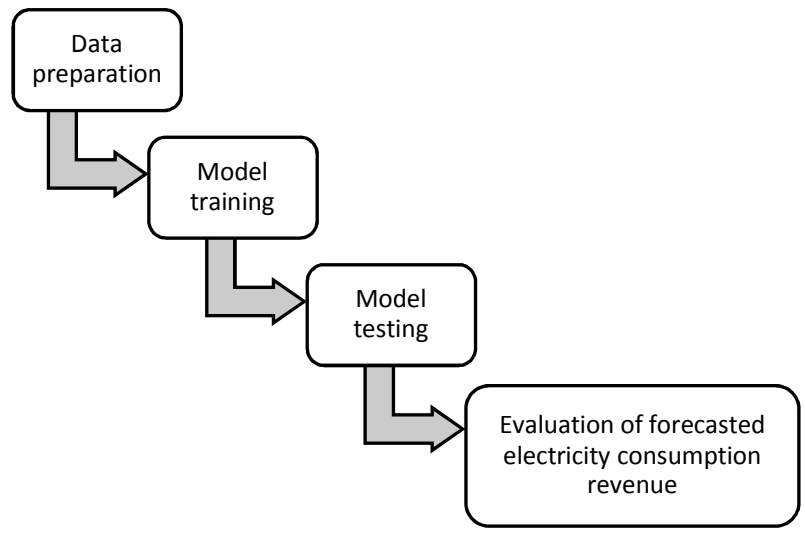

Fig. 1 Research Methodology

\section{A. Data preparation}

This research used secondary data of the electricity consumption obtained from the $500 \mathrm{kV}$ electricity system of Java-Bali area. The data was taken between January-March 2012 with a total of 4368 collected data. Each record in the data was captured every half an hour (30 minutes), starting from 00.00 AM to 11.30 PM each day.

Before starting the neural network model training, first, this data was divided into 7 groups. These 7 groups represents 7 days of the week, from Monday to Sunday. Each group contains electricity consumption load which occurred in each respective day of the week and sorted by date and time of occurrence. Therefore, the Monday group consists of all the electricity consumption that happened in Monday; from the first Monday of January 2012 at 00.00 AM to the last Monday of March 2012 at 11.30 PM. Sample electricity consumption data of the Monday group are displayed in Table 1.

After the data was grouped, to obtain the revenue, each electricity consumption load was then multiplied with the current electricity price or the TDL that year, as shown in (1).

$$
E C \operatorname{Rev}=T D L \times E C
$$

Where:

$$
\begin{array}{ll}
\text { EC Rev } & =\text { electricity consumption revenue } \\
\text { TDL } & =\text { Tarif Dasar Listrik / electricity rate } \\
\text { EC } & =\text { electricity consumption }
\end{array}
$$

According to the chart of TDL distributed by the Ministry of Communication and Information Technology of Indonesia, the electricity price that was current for the year 2012 is Rp. 1010,00. Therefore, for the year 2012, the revenues were calculated using (2). The sample data of the Monday group's electricity consumption revenue are available in Table 2.

$$
E C \operatorname{Rev}_{2012}=1010 \times E C_{20} 12
$$

Where:

EC $\operatorname{Rev}_{2012}=$ electricity consumption revenue for the year 2012

$\mathrm{EC}_{2012}=$ electricity consumption of the year 2012 
TABLE 1

SAMPLE ELECTRICITY CONSUMPTION DATA IN MONDAY GROUP (IN MVA)

\begin{tabular}{ccc} 
& (IN MVA) \\
\hline \hline & Monday & \\
January & February & March \\
\hline 12800 & 13538 & 14348 \\
12624 & 13275 & 14254 \\
12618 & 13202 & 14115 \\
12449 & 13034 & 13905 \\
12110 & 12916 & 13705 \\
12043 & 12773 & 13690 \\
11966 & 12688 & 13585 \\
11944 & 12678 & 13486 \\
12262 & 12909 & 13753 \\
12314 & 13218 & 13879 \\
12173 & 13451 & 14237 \\
11858 & 12965 & 13818 \\
11482 & 12520 & 13315 \\
11300 & 12223 & 13093 \\
11330 & 12299 & 13116 \\
11312 & 12264 & 13080 \\
11354 & 12509 & 13170 \\
11374 & 12613 & 13436 \\
11497 & 12811 & 13354 \\
11597 & 12927 & 13577 \\
11585 & 13050 & 13721 \\
11501 & 13006 & 13738 \\
11488 & 13048 & 13543 \\
11454 & 12895 & 13424 \\
11478 & 12909 & 13381 \\
\hline \hline
\end{tabular}

TABLE 2

SAMPLE ELECTRICITY CONSUMPTION REVENUE DATA IN MONDAY GROUP (IN RUPIAH)

\begin{tabular}{ccc}
\hline \hline & Monday & \\
January & February & March \\
\hline 12928000 & 13673380 & 14491480 \\
12750240 & 13407750 & 14396540 \\
12744180 & 13334020 & 14256150 \\
12573490 & 13164340 & 14044050 \\
12231100 & 13045160 & 13842050 \\
12163430 & 12900730 & 13826900 \\
12085660 & 12814880 & 13720850 \\
12063440 & 12804780 & 13620860 \\
12384620 & 13038090 & 13890530 \\
12437140 & 13350180 & 14017790 \\
12294730 & 13585510 & 14379370 \\
11976580 & 13094650 & 13956180 \\
11596820 & 12645200 & 13448150 \\
11413000 & 12345230 & 13223930 \\
11443300 & 12421990 & 13247160 \\
11425120 & 12386640 & 13210800 \\
11467540 & 12634090 & 13301700 \\
11487740 & 12739130 & 13570360 \\
11611970 & 12939110 & 13487540 \\
11712970 & 13056270 & 13712770 \\
11700850 & 13180500 & 13858210 \\
11616010 & 13136060 & 13875380 \\
11602880 & 13178480 & 13678430 \\
11568540 & 13023950 & 13558240 \\
11592780 & 13038090 & 13514810 \\
\hline \hline
\end{tabular}

\section{B. Model training}

Next step was designing and initializing the JRNN model. JRNN training consisted of two phases: the learning phase and the retrieving phase [19]. The learning phase of JRNN consists of (1) forward operation, where the original input are fed and calculated through the model to the output layer to produce the output; and (2) backward operation, where the learning algorithm of JRNN is implemented by copying the output to the context layer. The retrieving phase is where the output from the context layer, together with the same input fed in the learning phase, are inserted to the model once more to gain the final output [5], [17], [18]. Fig. 2 displays the architecture of JRNN in general [18], [19]. The variables $N I, N O, N C, N H$ are number of neuron units in the input, output, context, and hidden layer, respectively.

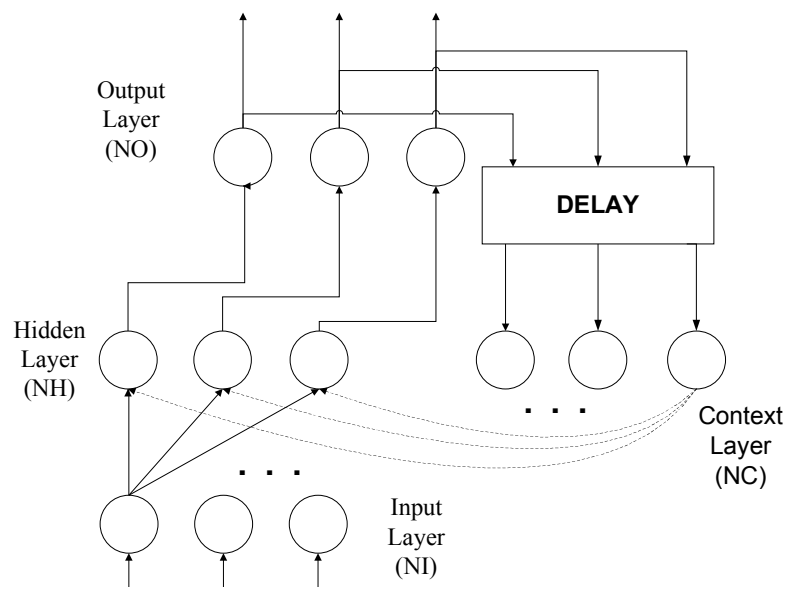

Fig. 2 Basic architecture of Jordan Recurrent Neural Network

The design of the JRNN model used in this work is displayed in Fig. 3 with each training parameters described as follows [20]. Three hidden layers were implemented, with $\mathrm{NH}_{1}=12, \mathrm{NH}_{2}=5$, and $\mathrm{NH}_{3}=1$ respectively. The number of neuron units in the input layer was $N I=2$. Only 1 neuron in input layer was assigned as the data input, because 
the size of the input vector was 1 , which is the electricity consumption revenue. The other neuron in input layer was an offset neuron which always produced output with the value of 1 [19].

The number of output layer was set to $N O=1$. The expected output was the predicted value of electricity consumption revenue for the same hour, same respective day of the week, in the future. The epoch was set to 4000, to avoid overwhelming cost in calculation but still maintaining a decent epoch number in order to obtain the best possible maximum result. The learning rate used was $\alpha=0.1$ and allowed error reward was set to $10^{-4}$.

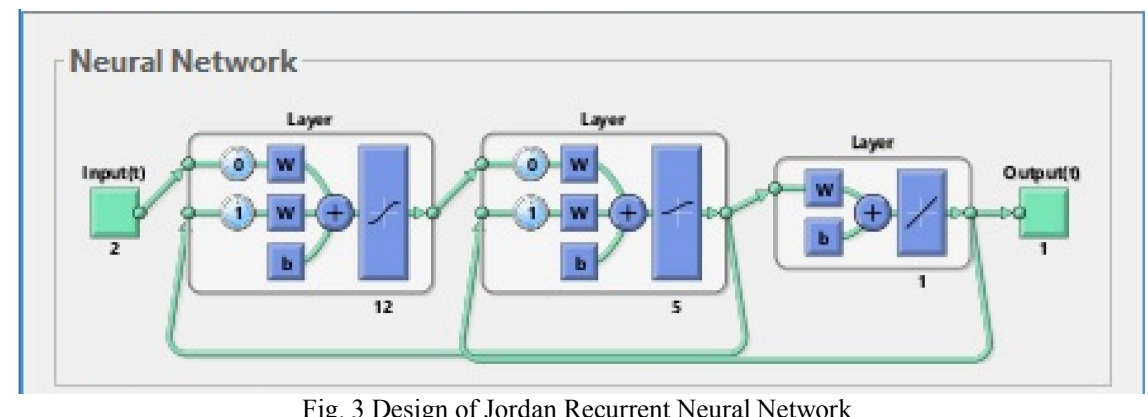

Fig. 3 Design of Jordan Recurrent Neural Network

\section{Model testing}

After all of the neural networks were trained, the next in line was to test the capability to forecast the electricity consumption revenue. Each of the 7 models was tested to predict the revenue for their respective day in the first week of April 2012. The prediction result then would be compared to the actual electricity consumption revenue of the first week of April 2012.

Furthermore, a traditional feed forward ANN was trained in the same procedure as the JRNN networks and then tested to assess each of the neural network's performance. The traditional feed forward ANN was also initialized with the identical parameter as the JRNN model and is shown in Fig. 4, except the extra nodes in hidden layer. The JRNN network in Fig. 3 had extra weight nodes in the hidden layer which represented context layer, meanwhile the traditional feed forward ANN in Fig. 4 doesn't have the same extra weight nodes.

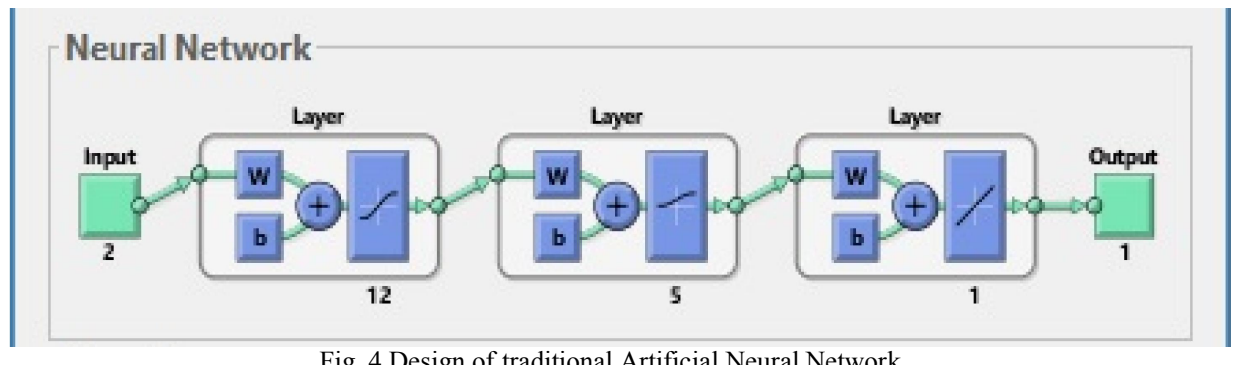

Fig. 4 Design of traditional Artificial Neural Network

\section{Evaluation of the forecasted electricity consumption revenue}

Two measurements were used to evaluate the performance of JRNN prediction result, Sum of Square Error (SSE) and Mean Square Error (MSE). SSE and MSE are negative-based Goodness of Fit measures which measure the error from a trained model. So, the lower the value, the better and the accurate the model is.

1) Sum of Square Error (SSE)

SSE is the sum of squared deviation between the predicted value and actual value. The SSE is calculated with (3) [11] as follows:

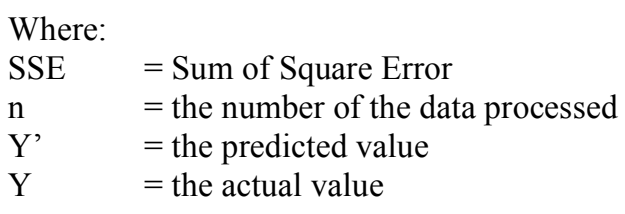

$$
S S E=\sum_{1}^{n}\left(Y^{\prime}{ }_{t-k}-Y_{t-k}\right)^{2}
$$


2) Mean Square Error (MSE)

MSE measures the average of the sum of square errors. The value of MSE is calculate with (4) [11] as follows:

Where:

$$
M S E=\frac{S S E}{n}
$$

MSE $\quad=$ Mean of Square Error

SSE $\quad=$ Sum of Square Error

$\mathrm{n} \quad=$ the number of the data observed

\section{RESULTS}

Fig. 5, Fig. 6, Fig. 7, Fig. 8, Fig. 9, Fig. 10, and Fig. 11 exhibit the plotting of the predicted revenues with JRNN model from the first week of April 2012 for Monday, Tuesday, Wednesday, Thursday, Friday, and Sunday, respectively. The plottings are drawn side by side with the actual revenues data for easy comparison.

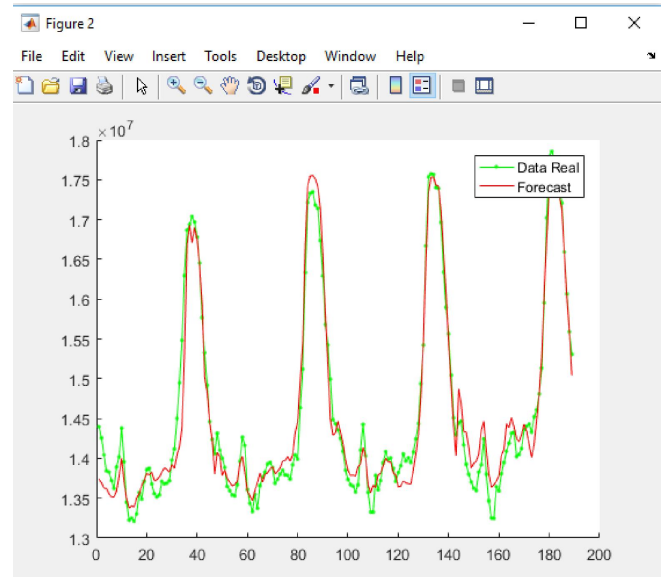

Fig. 5 Test result for Monday with JRNN

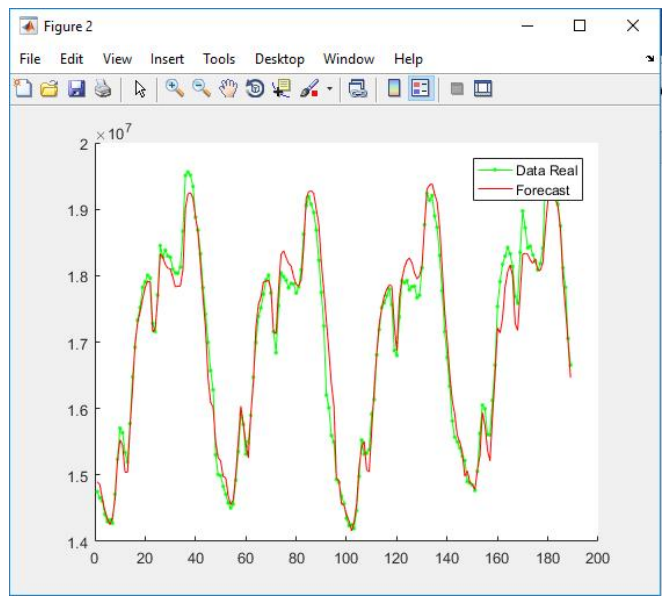

Fig. 7 Test result for Wednesday with JRNN

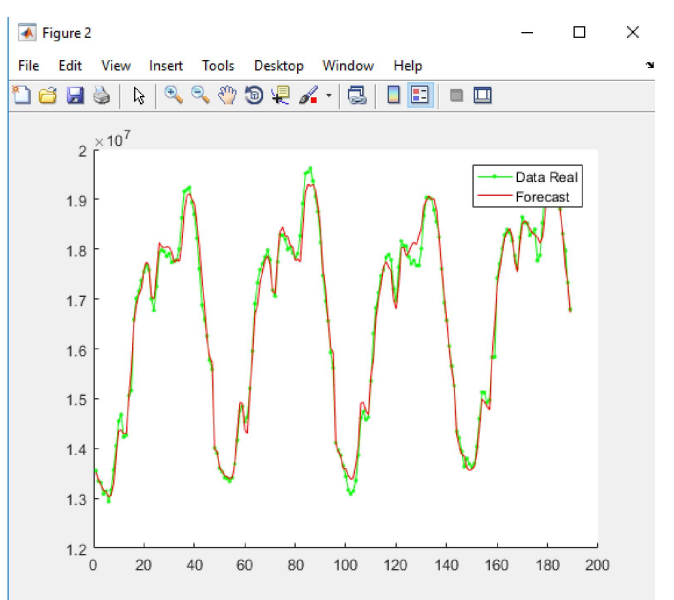

Fig. 6 Test result for Tuesday with JRNN

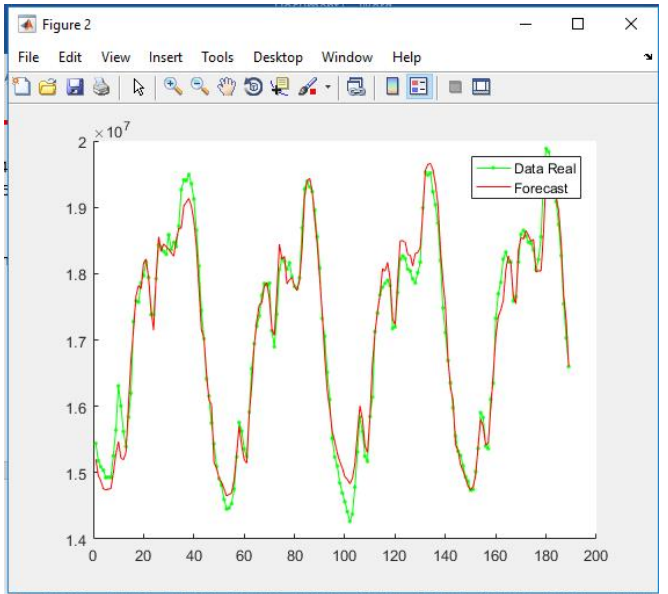

Fig. 8 Test result with JRNN for Thursday 


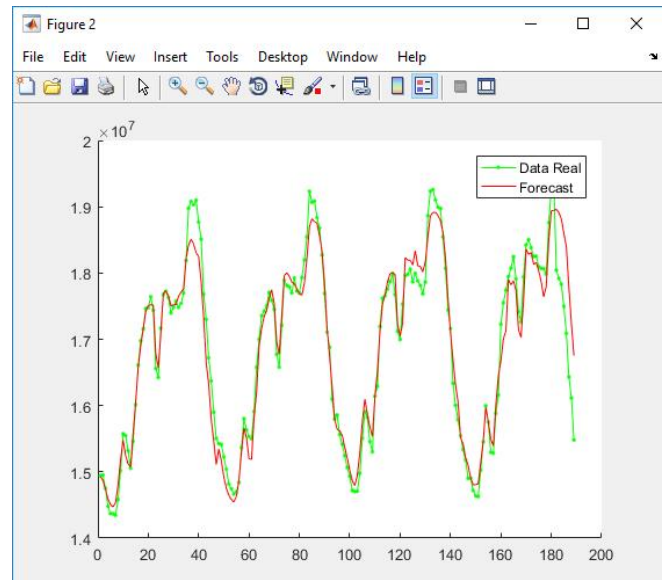

Fig. 9 Test result with JRNN for Friday

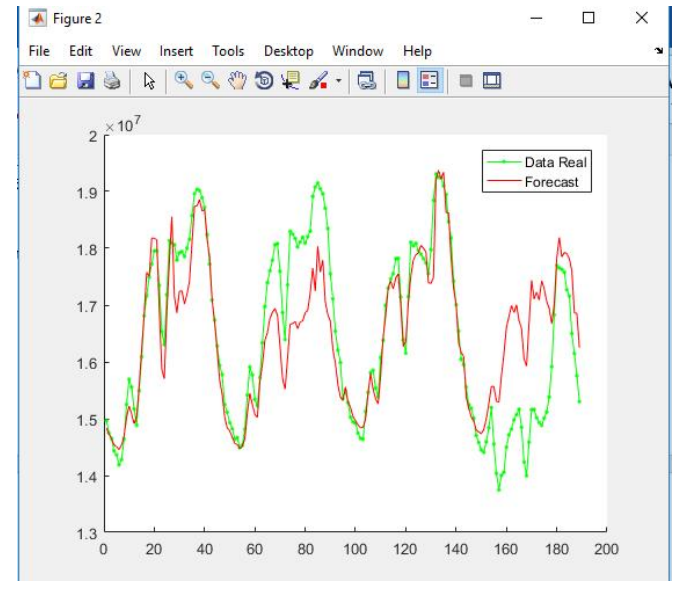

Fig. 10 Test result with JRNN for Saturday

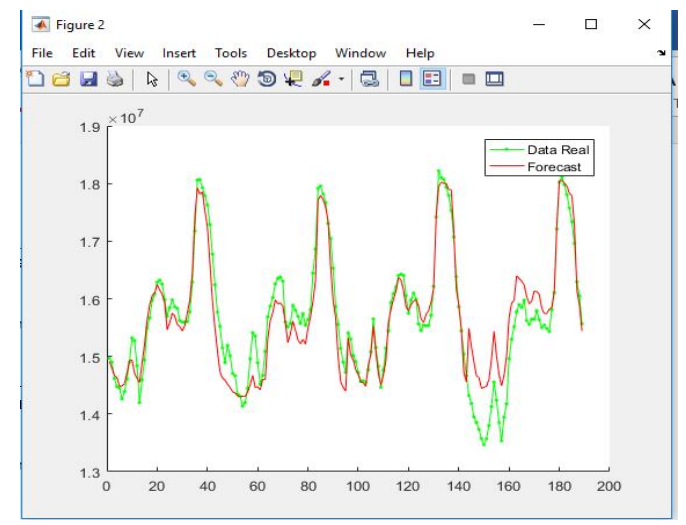

Fig. 11 Test result with JRNN for Sunday

Plotting of the predicted revenues from traditional feed forward ANN model drawn side by side with the actual revenues from the first week of April 2012, for Monday, Tuesday, Wednesday, Thursday, Friday, and Sunday are exhibited in Fig. 12, Fig. 13, Fig. 14, Fig. 15, Fig. 16, Fig. 17, and Fig. 18, respectively.

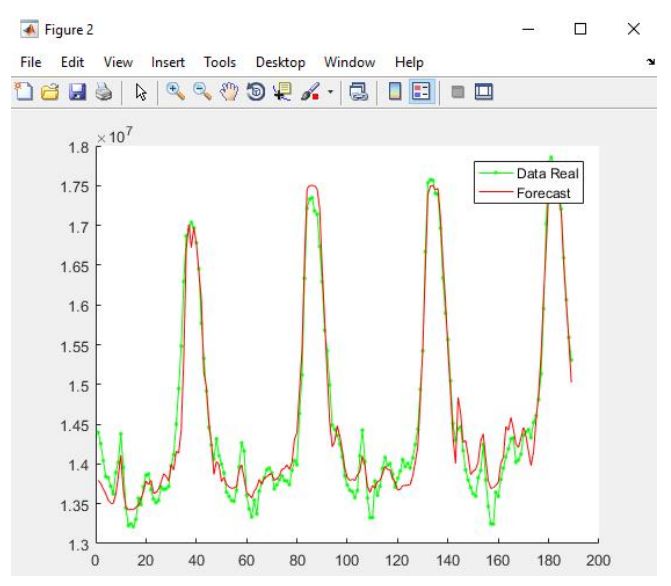

Fig. 12 Test result with traditional feed forward ANN for Monday

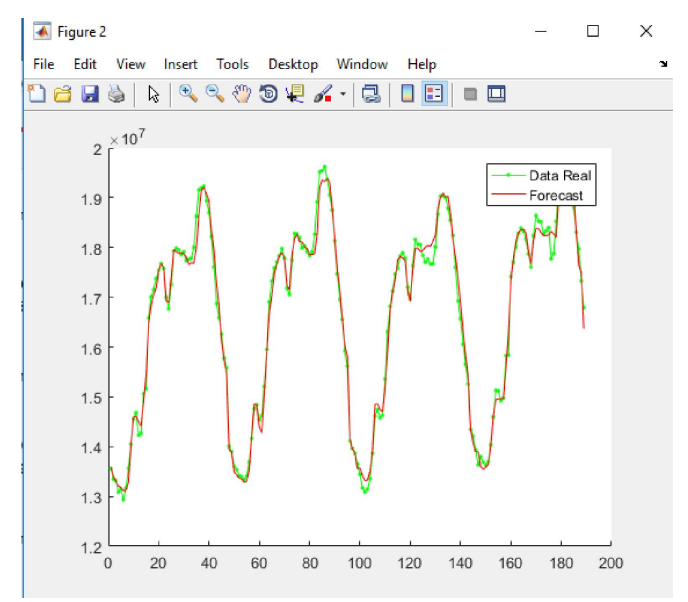

Fig. 13 Test result with traditional feed forward ANN for Tuesday 
At Figure 2

File Edit View Insert Tools Desktop Window Help

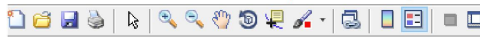

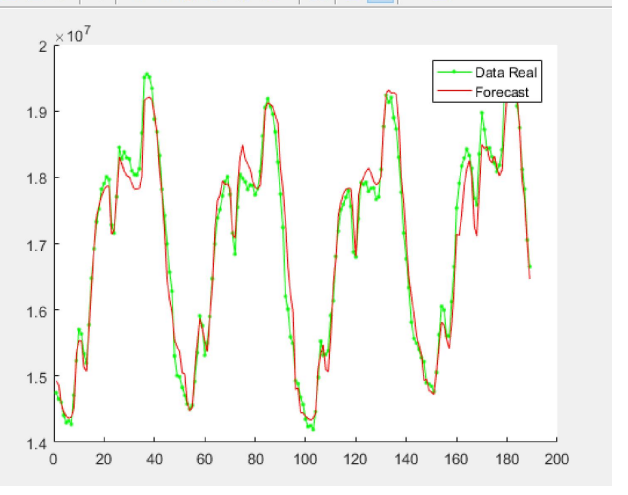

Fig. 14 Test result with traditional feed forward ANN for Wednesday

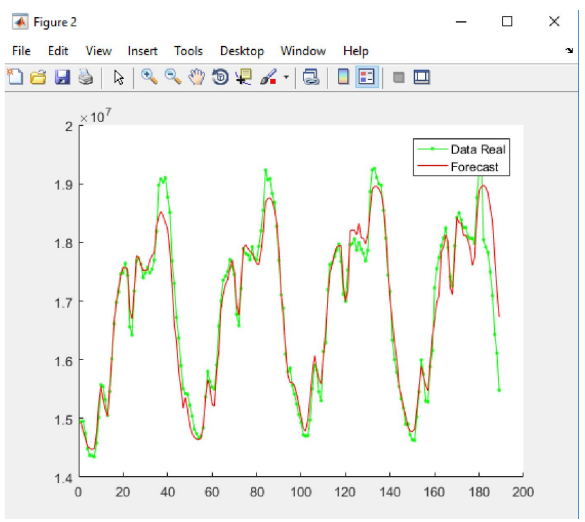

Fig. 16 Test result with traditional feed forward ANN for Friday
A. Figure 2

File Edit View Insert Tools Desktop Window Help

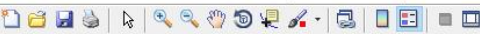

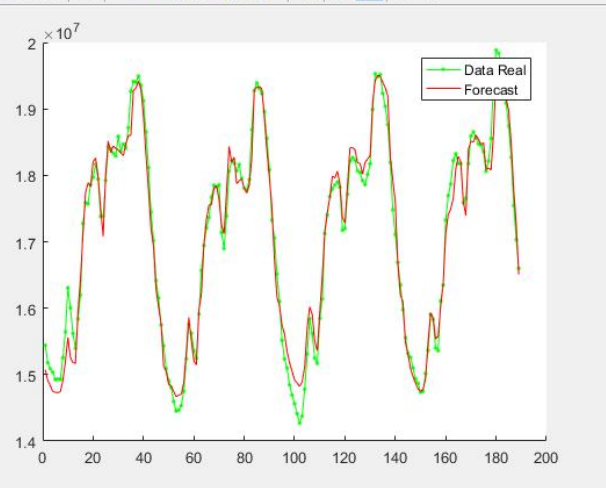

Fig. 15 Test result with traditional feed forward ANN for Thursday

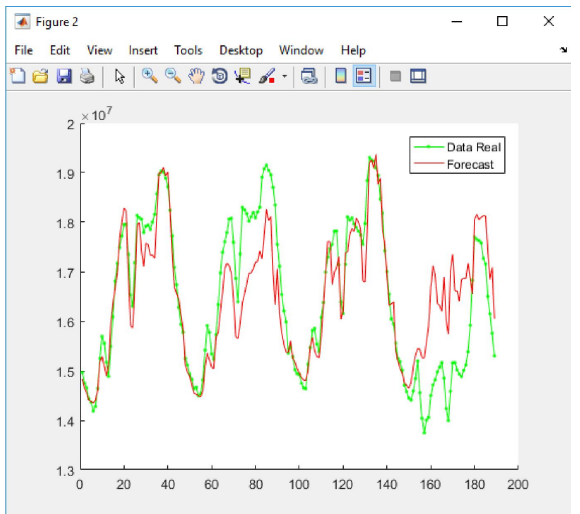

Fig. 17 Test result with traditional feed forward ANN for Saturday

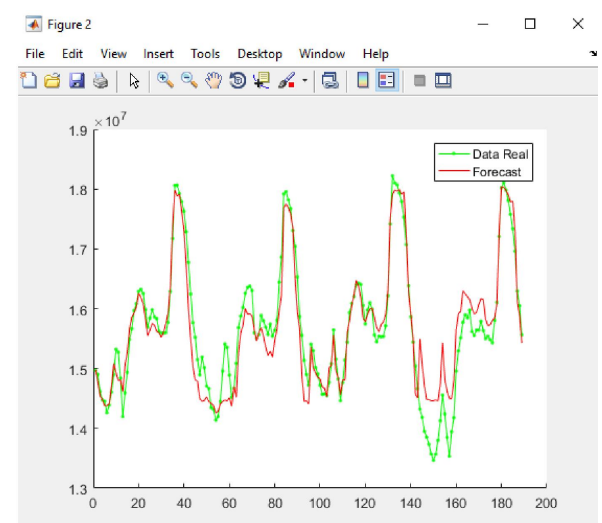

Fig. 18 Test result with traditional feed forward ANN for Sunday 


\section{DISCUSSION}

It is discernible from the plotting result for JRNN model (Fig. 5 to Fig. 11) that the JRNN model had successfully produced the expected result for weekdays. The same goes for the traditional feed forward ANN model. In fact, both JRNN model and traditional feed forward ANN model produced almost similar result. The predictions yielded were close to the actual electricity consumption revenues data for that day; particularly on Monday, Tuesday, and Thursday. However, both JRNN and traditional feed forward ANN failed quite poorly in forecasting the revenue for weekends, which for Indonesia falls on Saturday and Sunday. This result was to be expected. Weekends are categorized as special day, a holiday. Quoting from A. Dharma, et al., holidays' electricity consumption has different characteristic than those in normal days, such as weekdays. This is due to the fact the activities on holidays may vary compared to the normal routine in weekdays [6].

Table 3 presents the value of SSE and MSE along with the elapsed running time between JRNN model and traditional feed forward ANN model for each respective day of the week. The SSE and MSE values of JRNN were smaller than the SSE and MSE values of traditional feed forward ANN. Besides that, JRNN's elapsed simulation time was 0.615937 seconds faster than the traditional feed forward ANN. Therefore, from this evaluation, it can be concluded that JRNN performed better and faster forecasting task than traditional feed forward ANN.

TABLE 3

SSE AND MSE VALUES AND ELAPSED TIME OF THE TEST RESULT

\begin{tabular}{|c|c|c|c|c|c|c|}
\hline \multirow[b]{2}{*}{ Day of the Week } & \multicolumn{3}{|c|}{ "Jordan Recurrent Neural Network } & \multicolumn{3}{|c|}{ Feed forward Neural Network } \\
\hline & $\operatorname{SSE}\left(\mathrm{n} \times 10^{-4}\right)$ & $\operatorname{MSE}\left(\mathrm{n} \times 10^{-4}\right)$ & $\begin{array}{r}\text { Elapsed Time } \\
\text { (seconds) }\end{array}$ & $\operatorname{SSE}\left(\mathrm{n} \times 10^{-4}\right)$ & $\operatorname{MSE}\left(\mathrm{n} \times 10^{-4}\right)$ & $\begin{array}{r}\text { Elapsed Time } \\
\text { (seconds) }\end{array}$ \\
\hline Monday & 333.7633 & 1.7659 & 3.536408 & 336.0868 & 1.7782 & 3.379201 \\
\hline Tuesday & 303.0221 & 1.6033 & 3.549589 & 292.6983 & 1.5487 & 3.449062 \\
\hline Wednesday & 531.3772 & 2.8115 & 3.526271 & 533.8824 & 2.8248 & 3.419462 \\
\hline Thursday & 391.3536 & 2.0707 & 3.412383 & 391.1488 & 2.0696 & 3.431827 \\
\hline Friday & 293.5943 & 1.5534 & 3.515345 & 308.9408 & 1.6346 & 3.451698 \\
\hline Saturday & $1.1967 \times 10^{3}$ & 6.3319 & 3.426895 & $1.2359 \times 10^{3}$ & 6.5394 & 3.985247 \\
\hline Sunday & 736.5928 & 3.8973 & 3.489469 & 747.6463 & 3.9558 & 3.9558 \\
\hline Summary & 3787.1445 & 20.034 & 24.456360 & 3846.3034 & 20.3511 & 25.072297 \\
\hline$\times 10^{-4}$ & 0.3787 & 0.002 & & 0.3846 & 0.00203 & \\
\hline
\end{tabular}

The large SSE and MSE values on Saturday and Sunday for both JRNN and traditional feed forward ANN models strongly support the statement that week end has distinct and unique electricity consumption and revenue pattern which fairly differs from the consumption and revenue pattern on week days. On week days, Indonesia has fixed working hours. So accordingly, week days have regular and steady electricity consumption and revenue pattern. Meanwhile, on week end, when there is no work, human activities are varying greatly and nearly unpredictable. Hence, it yields in inconsistent electricity consumption and revenue pattern.

Despite the fact that weekends and weekdays were trained separately, the JRNN model still produced values with large error margin. Drawing from this result, it is suggested to train the JRNN model with different set of parameters and expand the dataset for weekend in order to capture the pattern.

\section{CONCLUSIONS}

The electricity demand for the Java-Bali area is undeniably high, thus making this area one of the largest source of electricity consumption revenue. Electricity consumption revenue is obtained from multiplying the current electricity price with the electricity consumption, therefore the revenue is proportional to the electricity consumption. Since the electricity consumption is ever-changing depending on the day of the week, an accurate prediction of revenue is essential to anticipate change in the future and to avoid losses in calculation of revenue.

This paper presents the task of short-term electricity consumption revenue on Java-Bali electricity system using Jordan Recurrent Neural Network (JRNN) and then the performance was assessed and compared with traditional feed forward Artificial Neural Network (ANN). The experiment showed that JRNN can forecast electricity consumption revenue and also performed the forecast task faster and more accurately than traditional feed forward ANN. From the experiment, it can also be drawn to conclusion that the electricity consumption in Java-Bali electricity system for weekdays has more consistent and constant value, rather than on weekends. 


\section{REFERENCES}

[1] N. Amjady, "Day-Ahead Price Forecasting of Electricity Markets by a New Fuzzy Neural Network," IEEE Transactions On Power Systems, vol. 21, no. 2, pp. 887-896, May 2006.

[2] Ö. F. Ertugrul, "Forecasting electricity load by a novel recurrent extreme learning," Electrical Power and Energy Systems, vol. 78 , pp. 429 $435,2016$.

[3] G. Aneiros, J. Vilar and P. Raña, "Short-term forecast of daily curves of electricity demand and price," Electrical Power and Energy Systems, vol. 80, pp. 96 - 108, 2016.

[4] W. Qun, Z. Yingbin, Z. Xinying, Q. Youming, W. Yize and Z. Zhisheng, "Short-term Load Forecasting Model Based on Ridgelet Neural Network Optimized by Particle Swarm Optimization Algorithm," in 8th IEEE International Conference on Software Engineering and Service Science (ICSESS), Beijing, 2017.

[5] P. F. Pai and W. C. Hong, "Forecasting regional electricity load based on recurrent support vector machines with genetic algorithms," Electric Power Systems Research, vol. 74, pp. 417 - 425, 2005.

[6] H. Nurohmah, D. Ajiatmo, D. Lastomo and I. Robandi, "Peramalan Beban Jangka Pendek Hari Libur Nasional dengan Interval Type-2 Fuzzy Inference System pada Sistem Jawa-Bali," in Sentia, Malang, 2015.

[7] M. Oveis Abedinia, N. Amjady and H. Zareipour, "A New Feature Selection Technique for Load and Price Forecast of Electrical Power Systems," IEEE Transactions on Power Systems, vol. 32, no. 1, pp. 62-74, 2016.

[8] P. Ayuningtyas, D. Triyanto and T. Rismawan, "Prediksi Beban Listrik pada PT.PLN (PERSERO) Menggunakan Regresi Interval dengan Neural Fuzzy," Jurnal Coding Untan, vol. 4, no. 1, pp. 1-10, 2016.

[9] T. Vantuch, A. G. Vidal, A. P. Ramallo-González, A. F. Skarmeta and S. Misák, "Machine Learning based Electric Load Forecasting for Short and Long-term Period," in IEEE 4th World Forum on Internet of Things (WF-IoT), Singapore, 2018.

[10] H. Chen, C. A. Cañizares and A. Singh, "ANN-based Short-Term Load Forecasting in Electricity Markets," in IEEE Power Engineering Society Winter Meeting Conference Proceedings (Cat. No.01CH37194), Columbus, OH, USA, 2001.

[11] M. Mordjaoui, S. Haddad, A. Medoued and A. Laouafi, "Electric Load Forecasting by Using Dynamic Neural Network," International Journal of Hydrogen Energy, vol. 42, pp. 17655-17663, 2017.

[12] M. Rana and I. Koprinska, "Forecasting electricity load with advanced wavelet neural networks," Neurocomputing, vol. 182, pp. 118-132, 2016.

[13] A. Dedinec, S. Filiposka, A. Dedinec and L. Kocarev, "Deep belief network based electricity load forecasting: An analysis of Macedonian case," Energy, vol. 115, pp. 1688-1700, 2016.

[14] W. He, "Load Forecasting via Deep Neural Networks," Procedia Computer Science, vol. 122, pp. 308-314, 2017.

[15] D. L. Marino, K. Amarasinghe and M. Manic, "Building Energy Load Forecasting using Deep Neural Networks," in 42nd Annual Conference of the IEEE Industrial Electronics Society, Florence, 2016.

[16] J. Zheng, C. Xu, Z. Zhang and X. Li, "Electric Load Forecasting in Smart Grid Using Long-Short-Term-Memory based Recurrent Neural Network," in Conference on Information Sciences and Systems (CISS), Baltimore, 2017.

[17] Z. C. Lipton, "A Critical Review of Recurrent Neural Networks for Sequence Learning," May 2015. [Online]. Available: http://arxiv.org/abs/1506.00019. [Accessed 1072018 ].

[18] M. I. Jordan, "Serial Order: A parallel distributed processing," Advances in Psychology, vol. 121, pp. 471-495, 1997.

[19] H. Hikawa and Y. Araga, "Study on Gesture Recognition System Using Posture Classifier and Jordan Recurrent Neural Network," in International Joint Conference on Neural Networks, California, 2011.

[20] Z. Kasiran, Z. Ibrahim and M. S. M. Ribuan, "Mobile Phone Customers Churn Prediction using Elman And Jordan Recurrent Neural Network," in 7th International Conference on Computing and Convergence Technology (ICCCT), Seoul, 2012. 